\title{
Severe hyperkalaemia and ketoacidosis during routine treatment with an insulin pump
}

\author{
GRAHAM KNIGHT, ADRIAN M JENNINGS, ANDREW J M BOULTON, \\ STEPHEN TOMLINSON, JOHN D WARD
}

Abstract

infusions of insulin; doctors could therefore be contacted at any time if patients encountered problems.

Initially, patients were taught individually by a doctor about the use of

During a feasibility study of the use of insulin pumps to treat diabetes ketoacidosis occurred at a rate of $0 \cdot 14$ episodes/patient/ year in the first year but was lower in subsequent years. A case of cardiac arrest secondary to hyperkalaemia during ketoacidosis occurred in a patient treated with a pump. The mean (SD) serum potassium concentration on presentation to hospital with ketoacidosis was significantly higher in patients treated with a pump $(5.7(1.1) \mathrm{mmol}(\mathrm{mEq}) / \mathrm{l})$ than those treated with conventional injections of insulin $(4.9(0.9) \mathrm{mmol} / \mathrm{l} ; \mathrm{p}<0.01)$.

The high rate of ketoacidosis and raised serum potassium concentrations during treatment with the pump creates doubt about the use of this treatment as an alternative regimen for large numbers of patients in a busy diabetic clinic.

\section{Introduction}

Continuous subcutaneous infusion of insulin is increasingly considered for routine clinical use, in addition to its original role in clinical research. ${ }^{1} \mathrm{~A}$ feasibility study of the use of continuous subcutaneous infusion of insulin in a busy diabetic clinic has been carried out in Sheffield to assess the practicality of the widespread use of this treatment. ${ }^{2}$ Other centres have described diabetic ketoacidosis as an important problem in patients treated with continuous subcutaneous infusion of insulin..$^{34}$

We report the results of a fe..sibility study of the use of continuous subcutaneous infusions of insulin as an alternative regimen to conventional treatment with injections and describe a case of cardiac arrest, apparently secondary to hyperkalaemia in diabetic ketoacidosis, that occurred in a patient treated with continuous subcutaneous infusion of insulin.

\section{Patients and methods}

Diabetic patients treated with insulin, aged 16-59, attending our clinic during a 10 month period were asked to participate in the study, as previously described. ${ }^{2}$ Before starting treatment with continuous subcutaneous infusion of insulin all patients were proficient in monitoring their blood glucose concentrations at home using BM Test Glycemie 20-800 strips (Boehringer Mannheim). Patients chose to enter either of two treatment groups: treatment with continuous subcutaneous infusions of insulin or conventional treatment with insulin by injections.

Continuous subcutaneous infusion of insulin was started after a two month run in period during which the patients attended hospital monthly. Treatment began on an outpatient basis ${ }^{5}$ with a Graseby MS 26 pump and purified porcine soluble insulin. A change of cannula was recommended at intervals of three days. Patients attended hospital four times during the first week, then weekly, and after one month at monthly intervals until the fourth month, when two monthly appointments were made. A 24 hour telephone cover service was available to patients receiving continuous subcutaneous

Royal Hallamshire Hospital, Sheffield S10 2JF

GRAHAM KNIGHT, MB, MRCP, research registrar ADRIAN M JENNINGS, $M B, M R C P$, registrar

ANDREW J M BOULTON, MB, MRCP, senior registrar

STEPHEN TOMLINSON, MD, FRCP, honorary consultant physician

JOHN D WARD, MD, FRCP, consultant physician

Correspondence to: Dr Knight. continuous subcutaneous infusions of insulin and verbal and written instructions were given. Instructions given to treat hyperglycaemia emphasised the importance of intensified monitoring of blood glucose concentrations at home, urinary ketone testing, and increased insulin dosage, usually by additional boluses but if necessary by increased basal infusion rate.

After four months rapid severe loss of metabolic control was clearly identified as a recurrent problem in those treated with continuous subcutaneous infusions of insulin; subsequently, this problem has been reported by other groups. ${ }^{34}$ Consequently a protocol of more aggressive action was recommended to the patients when glycaemic control deteriorated, including precise extra dosages of insulin, timing of blood glucose and testing of urinary ketones, examination of the infusion system, and early contact by telephone to the diabetic unit. Diabetic ketoacidosis was defined as ketonaemia and hyperglycaemia with symptoms of nausea, thirst, malaise, vomiting, and serum bicarbonate concentrations $\leqslant 15 \mathrm{mmol}$ $(\mathrm{mEq}) / 1$.

After the identification of severe hyperkalaemia as a potential problem in patients receiving continuous subcutaneous infusions of insulin who developed diabetic ketoacidosis the notes of all patients admitted to our unit since January 1982 with diabetic ketoacidosis were examined to assess clinical and biochemical features on admission. Measurements of emergency specimens of venous blood had been made with reference to the following normal ranges: sodium concentrations $130-147 \mathrm{mmol}(\mathrm{mEq}) / 1$; potassium concentrations $3 \cdot 3-5 \cdot 5 \mathrm{mmol}(\mathrm{mEq}) / 1$; bicarbonate concentrations $22-32$ $\mathrm{mmol}(\mathrm{mEq}) / 1$; and glucose concentrations $3 \cdot 5-5 \cdot 0 \mathrm{mmol}(64-90 \mathrm{mg} / 100 \mathrm{ml})$. Glycaemic control was assessed by measurement of glycosylated haemoglobin concentrations, the normal range being equivalent to $5 \cdot 8-7 \cdot 8 \%$.

Standard statistical methods (Student's $t$ test and coefficient of probability) were used.

\section{Results}

Sixty five patients received continuous subcutaneous infusions of insulin for more than two years, amounting to roughly 150 patient years' experience of the treatment. During the first year of the study nine episodes of diabetic ketoacidosis occurred in nine patients receiving continuous subcutaneous infusions $(0.14$ episodes/patient/year), and in the second year this was reduced significantly to four episodes in three patients $(0.06$ episodes/patient/year; $p<0.001)$. During the third year five episodes occurred in five patients $(0.08$ episodes/patient/year). Diabetic ketoacidosis was often precipitated at times of physical stress, particularly during infection: six episodes were associated with respiratory tract infections and six with gastroenteritis. One episode was due to non-compliance by the patient, and in three cases no precipitating factor was identified. No episode of diabetic ketoacidosis was associated with mechanical failure of the pump, but one occurred when the cannula became disconnected from the pump, and another occurred when the patient failed to detect an empty reservoir of insulin.

No patient who developed diabetic ketoacidosis while receiving continuous subcutaneous infusion of insulin had previously required admission for this problem since diagnosis of their diabetes.

The table shows mean serum potassium, sodium, bicarbonate, and blood glucose concentrations at the time of admission for both treatment groups, continuous subcutaneous infusions of insulin and conventional treatment with injections. Serum potassium concentrations were significantly higher in patients receiving continuous subcutaneous infusions $(p<0.01)$, though no othe $e^{-}$significant differences were detected.

In nine $(50 \%)$ of the episodes of diabetic ketoacidosis during treatment with continuous subcutaneous infusions of insulin supranormal potassium concentrations $(>5.5 \mathrm{mmol} / \mathrm{l})$ were noted, and six patients presented with concentrations $\geqslant 6.5 \mathrm{mmol} / 1$ ( $33 \%$ of all episodes). In comparison, of those patients receiving injections of insulin, significantly fewer episodes were accompanied by hyperkalaemia $(10(22 \%), \mathrm{p}<0.01)$, and in only two episodes $(4 \%)$ were serum potassium concentrations $\geqslant 6.5 \mathrm{mmol} / 1$ $(\mathrm{p}<0.001)$. In addition to the patient described below, three patients 
Biochemical results in patients receiving continuous subcutaneous infusions of insulin or conventional treatment with injections (values are means $(S D)($ and ranges))

\begin{tabular}{|c|c|c|c|c|c|c|c|c|}
\hline & $\begin{array}{c}\text { No of episodes of } \\
\text { diabetic ketoacidosis }\end{array}$ & $\begin{array}{c}\text { No of } \\
\text { patients }\end{array}$ & $\underset{(\text { years })}{\text { Age }}$ & $\begin{array}{c}\text { Duration of } \\
\text { diabetes } \\
\text { (years) }\end{array}$ & $\begin{array}{l}\text { Serum potassium } \\
(\mathrm{mmol} / 1)\end{array}$ & $\underset{(\mathrm{mmol} / 1)}{\operatorname{Serum~sodium}}$ & $\begin{array}{l}\text { Blood } \\
\text { glucose } \\
(\mathrm{mmol} / 1)\end{array}$ & $\begin{array}{c}\text { Serum bicarbonate } \\
(\mathrm{mmol} / \mathrm{l})\end{array}$ \\
\hline $\begin{array}{l}\text { Continuous } \\
\text { subcutaneous infusions }\end{array}$ & 18 & 13 & $\begin{array}{l}33(14) \\
(16-52)\end{array}$ & $\begin{array}{l}14(10) \\
(5-36)\end{array}$ & $\begin{array}{l}5 \cdot 7(1 \cdot 1)^{*} \\
(4 \cdot 1-8 \cdot 7)\end{array}$ & $\begin{array}{l}131 \cdot 5(4 \cdot 4) \\
(124-137)\end{array}$ & $\begin{array}{l}35 \cdot 9(18 \cdot 1) \\
(17 \cdot 3-74 \cdot 2)\end{array}$ & $\begin{array}{l}10 \cdot 2(3.5) \\
(2 \cdot 0-15 \cdot 0)\end{array}$ \\
\hline Injections & 45 & 24 & $\begin{array}{l}35(20) \\
(15-74)\end{array}$ & $\begin{array}{l}12(8) \\
(1-30)\end{array}$ & $\begin{array}{l}4 \cdot 9(0 \cdot 9) \\
(2 \cdot 9 \cdot 6 \cdot 8)\end{array}$ & $\begin{array}{l}135 \cdot 2(4 \cdot 1) \\
(125-143)\end{array}$ & $\begin{array}{r}31 \cdot 1(13 \cdot 1) \\
(9 \cdot 6-76 \cdot 8)\end{array}$ & $\begin{array}{r}9 \cdot 0(3 \cdot 2) \\
(2 \cdot 3-15 \cdot 0)\end{array}$ \\
\hline
\end{tabular}

" $\mathrm{p}<0 \cdot 01$

Conversion: SI to traditional units - Serum potassium: $1 \mathrm{mmol} / 1=1 \mathrm{mEq} /$. Serum sodium: $1 \mathrm{mmol} / 1=1 \mathrm{mEq} / 1$. Blood glucose: $1 \mathrm{mmol}=18 \mathrm{mg} / 100 \mathrm{ml}$. Serum bicarbonate: $1 \mathrm{mmol} / 1=1 \mathrm{mEq} / 1$.

receiving continuous subcutaneous infusions had electrocardiographical abnormalities on admission that were attributed to hyperkalaemia.

No significant difference was found in mean age and duration of diabetes between the two treatment groups. All patients receiving continuous subcutaneous infusions of insulin had been screened for diabetic complications $^{2}$ no more than one year before their episodes of ketoacidosis. Of the nine patients with hyperkalaemia, two had albuminuria, one with normal serum urea and creatinine concentrations and one with minimally raised concentrations (urea concentration $9.3 \mathrm{mmol} / 1(56 \mathrm{mg} / 100 \mathrm{ml})$, creatinine concentration $151 \mathrm{mmol} / 1(1708 \mathrm{mg} / 100 \mathrm{ml}))$. No evidence of diabetic complications was found in the remaining seven patients. No patient receiving injections of insulin had nephropathy. Two of the patients receiving injections were treated with bumetanide and oral supplements of potassium, but no other patient in either group was taking drugs known to affect the balance of potassium.

In the group receiving continuous subcutaneous infusions of insulin serum potassium concentrations on admission to hospital were inversely proportional to the glycosylated haemoglobin concentration before admission (all measured roughly one month before the episode of diabetic ketoacidosis $)(\mathrm{r}=-0.54, \mathrm{p}<0.05)$.

\section{CASE REPORT}

A 44 year old woman with an 18 year history of type I diabetes and two years of treatment with continuous subcutaneous infusion of insulin presented to hospital after five days of intermittent diarrhoea and severe deterioration in her clinical state during the night before admission. Previously she had been cooperative and well motivated with good glycaemic control (glycosylated haemoglobin concentration $8.6 \%$ ), normal serum electrolyte concentrations and renal function, and no diabetic complications. She required $0.7 \mathrm{U}$ of insulin $/ \mathrm{kg}$ daily ( $60 \%$ as basal infusion). Before going to bed she had felt well and had not measured her blood glucose. Her husband awoke the next morning to find her comatose with the infusion cannula disconnected from the pump, and she was admitted to hospital as an emergency.

Blood was drawn for measurement of glucose and electrolyte concentrations and treatment was started with intravenous isotonic saline. Within five minutes she had a cardiac arrest but was resuscitated. The initial biochemical results were plasma potassium concentration $8.7 \mathrm{mmol} / \mathrm{l}$; plasma sodium concentration $133 \mathrm{mmol} / \mathrm{l}$; bicarbonate concentration 2 $\mathrm{mmol} / \mathrm{l}$; urea concentration $8.7 \mathrm{mmol} / 1$ ( $52 \mathrm{mg} / 100 \mathrm{ml})$; blood glucose concentration $55 \cdot 2 \mathrm{mmol} / 1(994 \mathrm{mg} / 100 \mathrm{ml})$; and arterial $\mathrm{pH} 6 \cdot 8$. The increased plasma potassium concentration was confirmed by a second result of $8.7 \mathrm{mmol} / \mathrm{l}$, taken during resuscitation. Ketonaemia and ketonuria were present. She recovered but was left with residual memory impairment. A diagnosis of cardiac arrest secondary to hyperkalaemia due to diabetic ketoacidosis was made.

\section{Discussion}

Reported rates of metabolic decompensation leading to ketoacidosis during continuous subcutaneous infusion of insulin are similar to that found in our study, ${ }^{+6}$ and the randomised Kroc study showed increased rates of diabetic ketoacidosis during continuous subcutaneous infusion compared with conventional treatment. The high rate of diabetic ketoacidosis during the first year of continuous subcutaneous infusion of insulin in our study was subsequently reduced. This reduction was probably attributable to re-education of patients, increasing experience of patients and doctors, and the withdrawal of infusion by some patients who had encountered problems. Similarly, Bending et al reported reduced incidences of ketoacidosis after increased experience with continuous subcutaneous infusions of insulin.
In general, ketoacidosis was precipitated by intercurrent illness, and only two episodes were due to failure of delivery of insulin, though Peden et al reported this to be a more common cause of diabetic ketoacidosis.

Peden et al observed severe hyperkalaemia (serum potassium concentration $=7.5 \mathrm{mmol} / 1$ ) during three episodes of ketoacidosis related to continuous subcutaneous infusions of insulin. ${ }^{3}$ Matteri $e t$ $a l$, in a study of the metabolic effects of disruption on pump treatment, observed resultant severe hyperkalaemia, particularly in a patient with mild renal impairment. ${ }^{9}$

Insulinopenia has been suggested as an important factor in the diabetic's propensity to develop hyperkalaemia ${ }^{10}$; this may be particularly important during continuous subcutaneous infusion as withdrawal of the pump or failure to increase the rate of infusion at times of increased requirements probably leads to rapidly developing insulinopenia.

Serum potassium concentrations on admission to hospital were inversely proportional to glycosylated haemoglobin concentrations in the group treated with the pump. This implies that patients achieving less satisfactory control of diabetes during continuous subcutaneous infusion are not necessarily predisposed to this potentially dangerous complication compared with well controlled patients.

Teutsch et al concluded that continuous subcutaneous infusion of insulin was not associated with increased mortality but, nevertheless, described several cases of sudden and unexplained deaths in young patients and six cases of fatal diabetic ketoacidosis in patients less than 40 years of age. ${ }^{\text {" }}$ Clearly, sudden death of young people is a cause for concern, particularly when attributable to potentially avoidable causes.

At present, the potential problem of severe hyperkalaemia associated with ketoacidosis during treatment with a pump creates doubt about the feasibility of continuous subcutaneous infusion of insulin as an alternative regimen for routine clinical use in large numbers of diabetic patients.

G Knight is a Lilly research fellow, and S Tomlinson is a Wellcome Trust senior lecturer.

\section{References}

1 Pickup JC. Continuous subcutaneous insulin infusion as a treatment option: a perspective after seven years of research applications. Diabetic Medicine 1984;1:27-32

2 Knight G, Boulton AJM, Drury J, et al. A feasibility study of the use of continuous subcutaneous insulin infusion in a diabetic clinic: patient's choice of treatment. Diabetic Medicine 1984;1: 267 72

3 Peden NR, Braaten JT, McKendry JBR. Diabetic ketoacidosis during long-term treatment with continuous subcutaneous insulin infusion. Diabetes Care 1984;7:1-5

4 Mecklenburg RS, Benson EA, Benson JW, et al. Acute complications associated with insuli infusion pump therapy. Report of experience with 161 patients. FAMA 1984;252:3265-9.

5 Knight G, Boulton AJM, Drury J, Ward JD. Experience of the initiation of CSIl treatment on an outpatient basis. Diabetologia 1983:25:17

6 Irsigler K, Dritz H, Najemnik C. Fleissner M, Hagmueller G. Long term treatment with external and implanted insulin infusion devices. Diabetes 1984;34 (suppl 1):73a.

7 Kroc Collaborative Study Group. Blood glucose control and the evolution of diabetic retinopathy and allo

8 Bending JJ. Pickun JC Keen H. The comparative frequency of diabetic ketoacidosis and hypoglycaemic coma during continuous subcutaneous insulin infusion and conventional insulin hypoglycaemic coma during continuous subcu

9 Matteri R, Murphy MB, Kitabchi AE. Metabolic dysfunction during pump withdrawal in brittle diabetics. Diahete: 1982;31 suppi 2):269.

10 Detronzo $R$, Sherwin R, Dillingham $M$, Hendler R, Tamborlane W, Felig P. Insulinopenic hyperkalaemia: regulatory role of basal infusion levels in potassium homeostasis. 7 Clin Invev $1978 ; 61: 472-9$.

11 Teutsch SM, Herman WH, Dwier DM, Lane JM. Mortality among diabetic patients using continuous subcutancous insulin infusion pumps. N Fingl 7 .11ed 1984;310:361-8.

Accepted 11 7une 1985 